\title{
Comparison of Y-jet and OIL effervescent atomizers based on internal and external two-phase flow characteristics
}

\author{
Marek Mlkvik ${ }^{1, a}$, Matous Zaremba ${ }^{2}$, Jan Jedelsky ${ }^{2}$ and Miroslav Jicha ${ }^{2}$ \\ ${ }^{1}$ FME STU in Bratislava, Nam. Slobody 17, 81231 Bratislava, Slovak Republic \\ ${ }^{2}$ FSI BUT, Technicka 2896/2, 61669 Brno, Czech Republic
}

\begin{abstract}
Presented paper focuses on spraying of two viscous liquids ( $\mu=60$ and $143 \mathrm{mPa} \cdot \mathrm{s}$ ) by two types of twinfluid atomizers with internal mixing. We compared the well-known Y-jet atomizer with the less known, "outside in liquid" (OIL), configuration of the effervescent atomizer. The required liquid viscosity was achieved by using the water-maltodextrin solutions of different concentrations. Both the liquids were sprayed at two gas inlet pressures $(\Delta \mathrm{p}=0.14$ and $0.28 \mathrm{MPa})$ and various gas-to-liquid ratios (GLR $=2.5 \%, 5 \%, 10 \%$ and $20 \%)$. The comparison was focused on four characteristics: liquid flow-rate (for the same working regimes, defined by $\Delta \mathrm{p}$ and GLR), internal flow regimes, Weber numbers of a liquid breakup (We) and droplet sizes. A high-speed camera and Malvern Spraytec laser diffraction system were used to obtain necessary experimental data. Comparing the results of our experiments, we can state that for both the liquids the OIL atomizer reached higher liquid flow-rates at corresponding working regimes, it was typical by annular internal flow and higher We in the near-nozzle region at all the working regimes. As a result, it produced considerably smaller droplets than the second tested atomizing device, especially for GLR $<10 \%$.
\end{abstract}

\section{Introduction}

Twin-fluid atomizers can be found in various industrial applications such as internal combustion and gas turbine engines [1], process industry [2], spray coating [3], fire suppression [4] or food process engineering and spray drying [5].

They are favored for their capability to process highviscous liquids such as heavy fuels [6] or suspensions used in food processing industry. These atomizers also provide easy control of the individual spray parameters with lower atomizing gas consumption and lower input pressures than their externally mixed counterparts.

In this paper, we decided to provide a comparison of the Y-jet atomizer and OIL atomizer as the reaction to the lack of available systematic atomizers comparisons. Selected spraying devices differ in the design of their internal parts and mixing principles. Our aim was to investigate differences in the internal and external flows for spraying liquids of different viscosity under the same working parameters.

\section{Experiment}

Our experiments were performed on cold test bench equipped with eccentric screw pump at constant rotation speed used to drive the liquid into the atomizer. The liquid mass flow was controlled by a valve in bypass line. The atomizing gas (air) was provided by a house supply, and its pressure was controlled by pressure relief valve.

\footnotetext{
${ }^{\mathrm{a}}$ Corresponding author: marek.mlkvik@stuba.sk
}

This regulation was independent on the air mass flow. The test rig was also equipped with sensors and data acquisition system for measurements of flow parameters. All the experiments were performed at the room temperature.

The atomizers were operated under two input pressures of air $(\Delta \mathrm{p}=0.14$ and $0.28 \mathrm{MPa})$ and four ratios of gas and liquid mass flows (GLR $=2.5,5,10$ and $20 \%$ ).

The required liquid viscosity was achieved by using water-maltodextrin solutions of different concentrations (Table 1).

The high-speed camera (Olympus i-speed2) equipped with PENTAX TV lens $(50 \mathrm{~mm}$, fl:1.4) with extension rings of a total length of $25 \mathrm{~mm}$ was used to observe primary breakup of liquid in the near-nozzle area.

Droplet sizes were measured $100 \mathrm{~mm}$ downstream of the discharge orifice using a Malvern Spraytec laser diffraction system working on frequency $500 \mathrm{~Hz}$ [7].

Table 1. Physical properties of used water-maltodextrin solutions

\begin{tabular}{|c|c|c|c|c|}
\hline Label & $\begin{array}{c}\text { Maltodextrin } \\
\text { powder } \\
\text { concentration } \\
{[\mathbf{\%}]}\end{array}$ & $\begin{array}{c}\boldsymbol{\mu} \\
{[\mathbf{m P a} \cdot \mathbf{s}]}\end{array}$ & $\begin{array}{c}\boldsymbol{\sigma} \\
{[\mathbf{m N} / \mathbf{m}]}\end{array}$ & $\begin{array}{c}\mathbf{\rho} \\
{\left[\mathbf{k g} / \mathbf{m}^{3}\right]}\end{array}$ \\
\hline liq.1 & 40 & 60 & 74.54 & 1185 \\
\hline liq.2 & 45 & 143 & 74.26 & 1121 \\
\hline
\end{tabular}

$* \mu$-viscosity, $\sigma$ - surface tension, $\rho$ - density 


\subsection{Atomizers}

Investigated atomizers (Figure 1.) have different internal geometry, which leads to the different internal flows for the same working regimes and consequently to the different spray characteristics such as the primary breakup Weber number or droplet sizes.

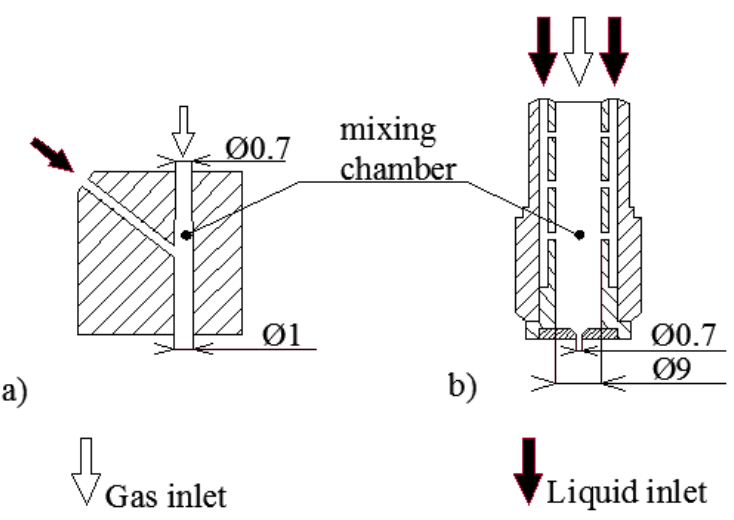

Figure 1. Schematic drawings of investigated atomizers

The mixing chamber of our Y-jet atomizer (Figure 1a) was designed according to the recommendations of Mullinger [8], and its cross-section diameter is $1 \mathrm{~mm}$. The working liquid is injected under the angle $52^{0}$ to the atomizer axis through a liquid injection port of diameter $0.4 \mathrm{~mm}$. The air is injected in the axial direction from the top of the mixing chamber.

The mixing chamber of the OIL effervescent atomizer (Figure. 1b.) has a cylindrical shape with cross-section diameter of $9 \mathrm{~mm}$. The internal two-phase flow is created by radial injection of the working liquid into the axial gas stream through 20 injectors with diameter $1 \mathrm{~mm}$. The two-phase mixture is discharged through the orifice of diameter $0.7 \mathrm{~mm}$.

The hydraulic resistance of internal design was judged by comparison of liquid flow-rates for corresponding $\Delta p$ and GLR. The influence of atomizers design on the internal two-phase flow was also investigated. The internal flow pattern was determined using liquid-to-gas momentum ratio $\left(\Phi=\mathrm{m}_{1}{ }^{2} \cdot \mathrm{d}_{1}^{2} \cdot \rho_{\mathrm{g}} \cdot \sin \Theta /\left(\mathrm{m}_{\mathrm{g}}{ }^{2} \cdot \mathrm{d}_{\mathrm{g}}{ }^{2} \cdot \rho_{\mathrm{l}}\right)\right.$, originally used by Song for $\mathrm{Y}$-jet nozzles [10]. The meaning of symbols in equation for $\Phi$ is the mass flux per surface unit, density, port diameter, and intersecting angle for "m", " $\rho$ ", " $d$ " and " $\Phi$ ". The indes "l " and " $g$ " denote the liquid or gas phases. The Weber number (We $=\rho \cdot \mathrm{w}^{2} \cdot \mathrm{D} / \sigma$, “w” denotes the liquid-to-gas velocity difference, where " $D$ " stands for the ligament diameter) of observed near-nozzle flows were calculated and used for comparison of primary breakup regimes of the atomizers. Finally, the spray quality was related to the measured Sauter mean diameter of the droplets.

\section{Results}

In this section, we provide a comparison of atomizers based on the four characteristics: liquid flow-rate (for the same working regimes), internal flows, Weber number of liquid breakup and droplet sizes.

\subsection{Internal flow: liquid flow-rates and flow pattern}

The atomizers were designed to work with the same liquid flow-rates at identical working regimes, but the measured data (Figure 2.) show that the real mass flows were significantly lower for the Y-jet atomizer. This difference wasmore significant for lower $\Delta \mathrm{p}$ and GLR $<10 \%$ for the more viscous liquid. Considering the dimensions of atomizers mixing chambers, the maximum mixture velocity, calculated from maximum measured mass flows, reached $40 \mathrm{~m} / \mathrm{s}$ for the $\mathrm{Y}$ jet atomizer, while it reached only $0.6 \mathrm{~m} / \mathrm{s}$ for the OIL atomizer. The friction pressure loss was therefore dominant in the case of the Yjet atomizer. On the other hand, the local pressure loss was significant at the discharge orifice of the OIL atomizer. It was caused by the narrow cross-section reduction (from $9 \mathrm{~mm}$ to $0.7 \mathrm{~mm}$ ) while it was less significant for the Y-jet atomizer. We thus presume that the mass flow difference of the atomizers was caused by the above-described relevance of local (viscosity independent) and friction (viscosity dependent, [9]) pressure losses.

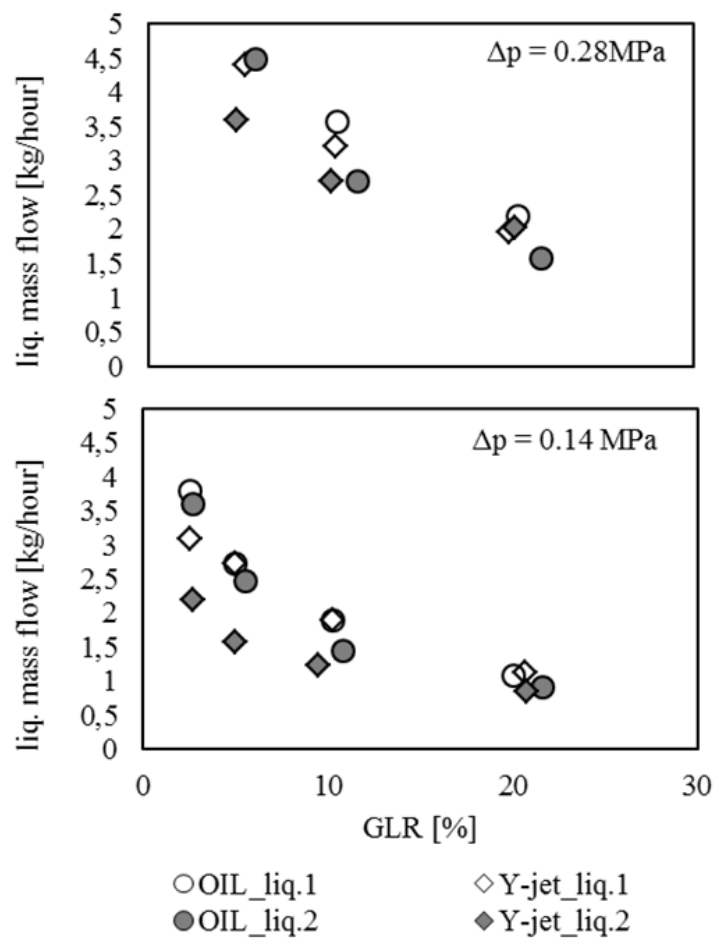

Figure 2. Measured mass flows of liquid

The design of the mixing chamber also influenced the internal flow pattern. Because the mixing principle for both the atomizers was the same - injection of liquid into the gas stream - we could estimate the internal flow patterns by the parameter $\Phi[10]$. Figures 3 and 4 show, that the internal flow patterns were different for the corresponding working regimes. The main difference between the atomizers was that the internal flow of the OIL atomizer was annular amongst all measured regimes. 
The gas velocity in the mixing chamber of the OIL atomizer was low, sothe annular liquid flow was not accelerated intensively, but the flow pattern was stable which led to the production of stable spray [7]. In the Yjet atomizer the liquid could reach the central portion of the mixing chamber. As a result, it was intensively accelerated by the surrounding high-velocity gas. The gas-to-liquid interaction also caused the flow instabilities as referred by Song [10] and decreased the spray stability [7].

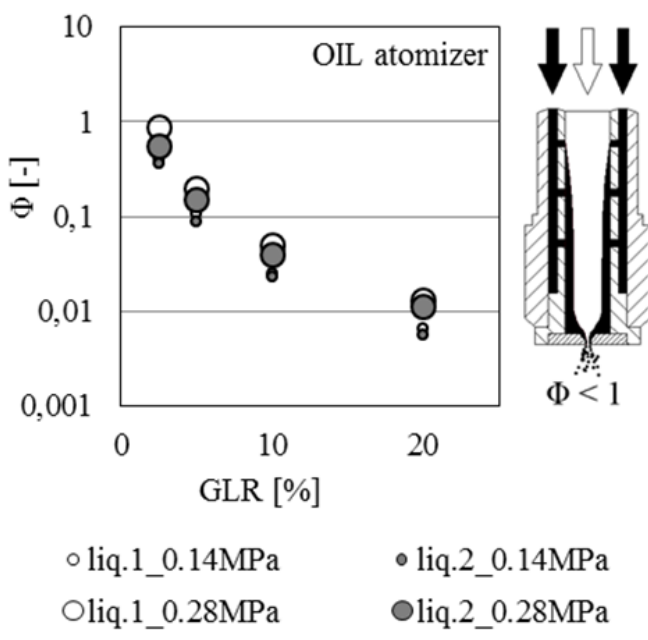

Figure 3. Estimated internal flow of the OIL atomizer

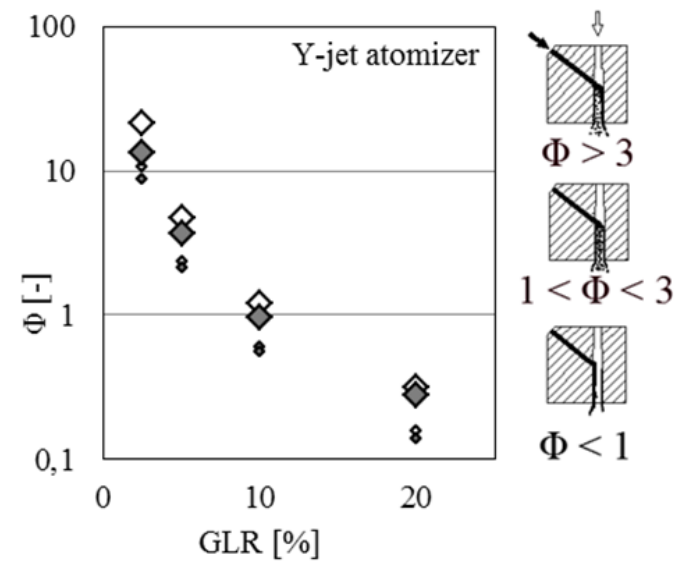

$$
\begin{array}{ll}
\diamond \text { liq.1_0.14MPa } & \diamond \text { liq.2_0.14MPa } \\
\diamond \text { liq.1_0.28MPa } & \diamond \text { liq.2_0.28MPa }
\end{array}
$$

Figure 4. Estimated internal flows of the Y-jet atomizer

\subsection{External flow: liquid breakup and droplet sizes}

The liquid discharge of the Y-jet atomizer was characterized by low We (Figure 5). The liquid acceleration in the mixing chamber decreased the liquidto-gas velocity slip in the discharge area. Therefore, $\sigma$ became the dominant force of the droplet deformation, which caused a number of spherical droplets observed in the near-nozzle flow of the Y-jet atomizer [7]. The We observed for the OIL atomizer were considerably larger regardless to the working regime or liquid viscosity. In this case, the air drag force deformed the liquid into fibers and potentially disrupted the large liquid structures [7].
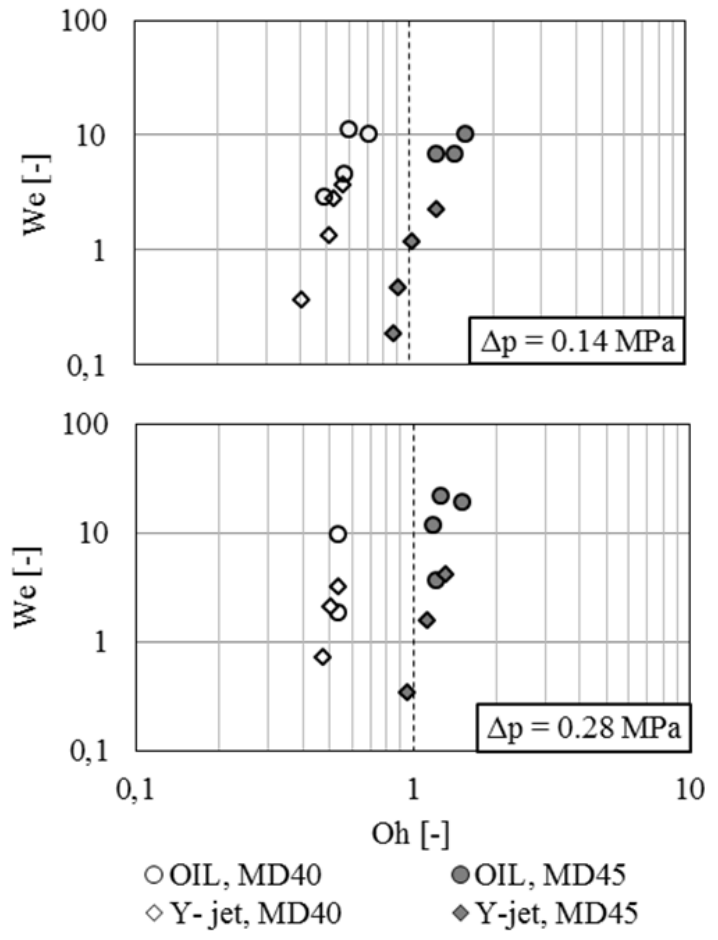

Figure 5. Weber's numbers of the near-nozzle flows

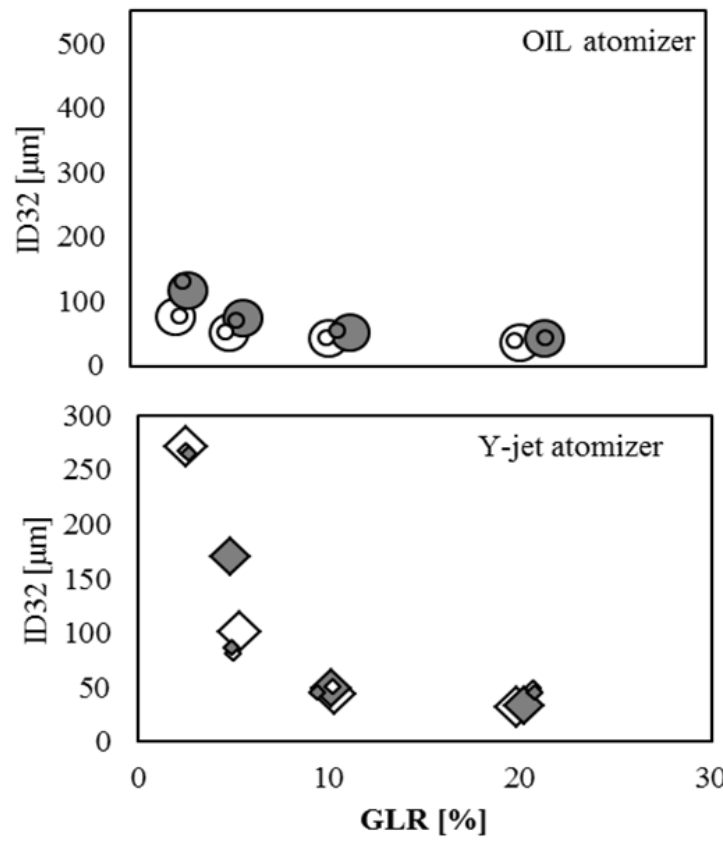

$$
\begin{array}{ll}
\diamond \text { liq. 1_0.28 MPa } & \diamond \text { liq. } 2 \_0.28 \mathrm{MPa} \\
\diamond \text { liq. 1_0.14 MPa } & \diamond \text { liq. } 2 \_0.14 \mathrm{MPa}
\end{array}
$$

Figure 6. Measured ID32 in distance $100 \mathrm{~mm}$ from the discharge orifice 
The liquid structures, observed in the near-nozzle region, were further fragmented and their size was reduced until they reached the stable spherical shape as the effect of surface tension. These droplets were observed in the distance $100 \mathrm{~mm}$ from the discharge orifice and their size were measured by the laser diffraction system. As shown in Figure 6, the general trend for both the atomizers shows a decrease of ID32 with increasing GLR, which accords to the number of previous works $[11,12,13]$. The $\mathrm{Y}$-jet atomizer produced spray with ID $32<50 \mu \mathrm{m}$ for GLR $=10$ and $20 \%$ for both the liquids, which can be considered as good quality for such viscous liquids. The ID32 rapidly increased up to $270 \mu \mathrm{m}$ with GLR reduction to 5 and $2.5 \%$ respectively. The OIL atomizer produced spray with smaller droplets for low GLRs. The ID32 rose up at lower GLRs, but the increase was not as rapid as in previous case. This atomizer also showed higher sensitivity to liquid viscosity, especially for low GLRs.

\section{Conclusions}

We studied flow and spray characteristics of a Y-jet atomizer in comparison with OIL effervescent atomizer. Our tests demonstrate a reduction of liquid flow-rate for the $\mathrm{Y}$-jet atomizer for the corresponding working regimes as the result of the atomizer mixing chamber design. The slow mixture motion in the OIL atomizer mixing chamber and its rapid acceleration in the discharge orifice produced a local (nearly viscosity) pressure loss. The pressure loss of the Y-jet atomizer was produced mainly by liquid internal friction, due to the high velocity of the internal flow.

The geometry of the mixing chamber also influenced the internal flow pattern of the atomizers. We estimated and compared internal two-phase flow types of investigated atomizers and we found that the internal flow of the OIL atomizer was annular for all measured regimes, while three types of internal flow patterns were identified for the $\mathrm{Y}$-jet atomizer over the range of tested working regimes. The main influence of the internal flow regime on the atomizer performance can be found in the spray stability as published in our previous works.

The internal flow also influenced the near-nozzle flow and primary breakup of the liquid. The liquid discharge of the Y-jet atomizer was characterized by the low We, which was caused by the liquid acceleration in the mixing chamber. The We observed for the OIL atomizer were considerably larger for all of the measured cases.

Different conditions of the near-nozzle flow affected the droplet sizes of the final spray. The Y-jet atomizer produced considerably larger droplets as the result of the low effect of the air drag force in the near-nozzle region. The OIL atomizer, characterized by larger We number of the primary breakup, produced smaller droplets, especially for the low GLRs

Considering the previous analysis, we can state that the OIL atomizer provided better results for all investigated working regimes. It reached higher flowrates at corresponding $\Delta \mathrm{p}$ and it also produced smaller droplets even for low GLRs. Thus, it fulfilled the task to atomize viscous liquids more effectively than the investigated $\mathrm{Y}$-jet atomizer (for given range of liquid viscosities and working regimes).

\section{Acknowledgements}

This work has been supported by the project No. GA1509040S funded by the Czech Science Foundation, the project LO1202 NETME CENTRE PLUS with the financial support from the Ministry of Education, Youth and Sports of the Czech Republic under the "National Sustainability Programme I" and project Reg. No. FSI-S14-2355 funded by the Brno University of Technology.

The authors also appreciate support from Prof. Dr.-Ing. Heike P. Schuchmann, Dr. rer. nat. Dipl.-Ing. Volker Gaukel and Dipl.-Ing Philipp Stähle from Karlsruhe Institute of Technology for providing us their test rig for experiments and other support and cooperation.

\section{References}

1. A.H. Lefebvre, 1988. Indian Defence Sci. J. 38, (1988)

2. D. Loebker, H.J. Empie, Proc.10th Annual Conference on Liquid Atomization and Spray Systems, pp. 253-257, (1997)

3. L.J. Qian, J.Z. Lin, H.B. Xiong, Int. J. Therm. Sci. 50, 1417-1427, (2011)

4. X. Huang, X.S. Wang, G.X. Liao, Proc. Combust. Inst. 33,pp. 2573-2579, (2011)

5. P. Stähle, V. Gaukel, H.P. Schuchmann, Food Research International, (2015)

6. J. Jedelsky, M. Jicha, J. Slama, J. Otahal, Energy Fuels 23, pp. 6121-6130, (2009)

7. M. Mlkvik, P. Stähle, H.P. Schuchmann, V. Gaukel, J. Jedelsky, M. Jicha, Int. J. Multiphase Flow 77, pp. 19-31, (2015)

8. P. J. Mullinger, N.A. Chigier, J. Inst. Fuel 47, pp. 251-261 (1974)

9. S. K. Chen, A. H. Lefebvre, Atomization sprays 4, pp. 275-290, (1994)

10. S.H. Song, S.Y. Lee, Atomization Sprays 6, pp. 193-209, (1996)

11. J.D. Whitlow, A.H. Lefebvre, Atomization Sprays 3, pp.137-155, (1993)

12. E. Sher, M. Koren, D. Katoshewski, V. Kholmer, Proc. ILASS-Europe, Paper II.7, (2000)

13. S. Sovani, P. Sojka, A. Lefebvre, Prog. Energ. Combust. 27(4), (2001) 